\title{
Socio-economic Aspects of Goat Production in a Rural Agro-pastoral System of Uganda
}

\author{
Charles Byaruhanga ${ }^{1, *}$, James Oluka ${ }^{2}$, Stephen Olinga ${ }^{1}$ \\ ${ }^{1}$ Nabuin Zonal Agricultural Research and Development Institute, National Agricultural Research Organisation, Uganda \\ ${ }^{2}$ National Livestock Resources Research Institute, Uganda
}

Copyright (C) 2015 by authors, all rights reserved. Authors agree that this article remains permanently open access under the terms of the Creative Commons Attribution License 4.0 International License

\begin{abstract}
A study was conducted to document the socio-economic aspects of goat production in Teso region, Uganda. Data was collected by using a questionnaire administered to 114 purposively selected goat owners. Majority $(87 \%)$ of de fecto household heads were male. About $41.2 \%$ of the farmers were aged $\geq 51$ years. The average number of goats per household was 9.2 (range 3-31). Most farmers (63.2\%) owned $\leq 5$ acres of land. Indigenous goats were mainly acquired by buying $(85 \%)$ while exotic goats and their crosses were acquired from government programs (34\%). Goats have a number of roles, though mainly kept as a source of cash income $(98.2 \%)$, followed by socio-cultural values (69.3\%). A large percentage of farmers (67\%) earned $\leq$ US $\$ 40$ p.a from goat production. The biggest problem in marketing of goats was high taxation. Majority of goat owners were men $(84.86 \%)$ but a few cases (average $15.14 \%$ ) of women that owned goats independently were also reported. Women and children participated less in decision making, although they were responsible for many goat production related activities. In conclusion, goat production can play an important role in improving rural livelihoods. Commercialisation, especially targeting women and youths would be desirable for improved profitability of smallholder production systems.
\end{abstract}

Keywords Goat Production, Income, Livelihood, Marketing, Teso

\section{Introduction}

Goats are important in resource-poor communities because they provide tangible benefits such as cash income from animal sales, meat for home consumption, manure, skins, and fiber [1,2]. They are also a source of intangible benefits, e.g. savings, insurance, and for socio-cultural purposes $[3,4]$. An estimated 39\% of households in Uganda are known to own goats, which further demonstrates the importance of goats in the livelihoods of the people [5]. In
Uganda, the population of goats is estimated at about 14.6 million, of which about $90 \%$ are indigenous [6]. The goat population has increased by $14 \%$ over the last six years. The growth of the goat sub-sector is attributable to increasing local and regional demand for better human nutrition especially meat $[5,7,8]$. The major indigenous goat breeds in Uganda include: Mubende, Kigezi, and Small East African (SEA). In order to improve on the productivity of goats, farmers in Uganda have adapted exotic goats such as Boer and Toggenberg and their crosses with indigenous breeds [2].

The Teso Farming System (TFS) comprises nine districts in eastern Uganda. The system is agro-pastoral with rural communities heavily dependent on subsistence mixed annual cropping and livestock production for their livelihoods [9]. About 7.5\% of Uganda's goat population is found in Teso region [6].

In order to improve goat productivity and marketing, it is important to have in place appropriate intervention measures. This requires a good understanding of the characteristics of the goat production systems [10,11]. Farmers' socio-economic and personal attributes have been identified as being instrumental to their access and utilisation of various technologies 12,13]. Moreover, it is important to have knowledge of the reasons why farmers keep goats in order to improve goat breeding, health and feeding interventions. However, the Teso faming system has not received adequate attention in studies on small ruminant production.

The objective of the present study was therefore; to establish the socio-economic situation of the goat enterprise in the Teso region, identify critical constraints and opportunities which could impact on the potential expansion of the goat farming activities. This information provides a basis for intervention programs that can sustain and increase goat productivity and as a result meet the needs and demands of human communities.

\section{Materials and Methods}




\subsection{Description of the Study Area}

The study was conducted in the Teso region of eastern Uganda between 2012 and 2013. The region is composed of nine districts and is a typical representative of rural areas in Uganda. It is home to an estimated 2.4 million people of Iteso and Kumam ethnicities. The total land coverage is $14,855 \mathrm{sq} \mathrm{km}$ (UBOS, 2014). The area experiences a humid and hot climate, receiving bimodal rainfall with an annual average between 1,000 to $1,350 \mathrm{~mm}$, much of which is received between March and May. There are decreasing light showers between June and August and heavier rains gain between September and November. The dry season begins in December up to February. Minimum and maximum temperatures are $18^{\circ}$ and $31.3^{\circ} \mathrm{C}$, respectively. However, extremes usually occur in February, when the temperatures can exceed $35^{\circ} \mathrm{C}$.

\subsection{Sampling and Data Collection}

A total of 114 households from Kumi $(\mathrm{n}=27)$, Kaberamaido $(n=25)$, Soroti $(n=23)$, Katakwi $(n=19)$ and Pallisa $(n=20)$ districts were sampled for the study. This was using prior information obtained from the field staff. All the goat keepers approached were willing to participate, and were then interviewed. A questionnaire, which was a slight modification of that designed by Rowlands et al. [14], was used to obtain information from respondents on the general household characteristics, acquisition and importance of goats, type and number of livestock kept, sales and marketing of goats and the gender aspects of goat production. The questionnaire was tested before the survey started, to ensure that all questions were clear to the interviewees. The questionnaire consisted of both open and close ended questions, and it was administered by a team of trained enumerators.

\subsection{Statistical Analysis}

Chi-square $\left(\chi^{2}\right)$ values and Pearson correlation coefficients were used to test the associations between districts, herds and household characteristics, using PASW ${ }^{\circledR}$ Statistics 18 (Predictive Analytics Software). Analysis of Variance (ANOVA) and independent samples T-test were also used to compare the significance of difference in means of continuous variables. Indices were calculated to provide overall ranking of reasons for keeping goats according to the formula: index $=$ sum of [ 3 for rank $1+2$ for rank $2+1$ for rank 3] given for an individual use divided by the sum of [3 for rank $1+2$ for rank $2+1$ for rank 3 ] summed over all uses.

\section{Results}

\subsection{Gender, Education Level and Source of Livelihood}

Of the households surveyed ( $\mathrm{n}=114)$, only $13.3 \%$ of the farmers were female. Most household heads in the area $(84.1 \%)$ had attained formal education: primary $(52.6 \%)$, secondary (21.9\%) and tertiary (9.6\%). Although all informants indicated crop farming and livestock keeping as important activities in their livelihoods, majority of the households (92.1\%) ranked crop farming as the first livelihood activity (Table 1). Only 5.3\% and $2.6 \%$ regarded livestock keeping and regular employment, respectively, as their first livelihood activities. Off-farms activities such business related activities were also reported. Of the livestock types kept, goats were kept in biggest numbers ( $\mathrm{p}<$ 0.001 ), on average 9 (range 3-31), as compared to cattle (6), sheep (3) and pigs (1). Goat herds were generally small. Fifty-five point three percent of the farmers (55.3\%) owned small herds (1-8 goats), 39.5\% owned medium size herds (9-19 goats), while only 5.3\% owned large herds of 20 or more goats. There was no significant association between district and the proportion of goat herds. Indigenous breeds were most common (64\%) followed by crosses between indigenous breed and South African Boer goats (29\%), and a few were pure exotic breeds (7\%).

Table 1. Ranking of source of livelihood in households

\begin{tabular}{ccc}
\hline Source of livelihood & Households $^{\mathrm{a}}$ & Households $^{\mathrm{b}}$ \\
\hline Crops & 114 & 105 \\
Livestock & 114 & 6 \\
Business (retail & 24 & 0 \\
shopping) & 4 & 3 \\
Regular employment & 2 & 0 \\
Casual labor & & \\
\hline
\end{tabular}

${ }^{\text {a }}$ Households that considered activity as important source of livelihood $(\mathrm{n}=$ 114).

${ }^{\mathrm{b}}$ Households that ranked source of livelihood as number one.

\subsection{Household Size and Age Structures and Land Holdings}

In general, for most households (58.8\%), the age of the household heads fell within the range of 18-50 years. However, a considerable proportion of farmers $(41.2 \%)$ were 51 years and above. Most households had 6-9 members (43\%) or more than 9 members $(44.7 \%)$ compared $(\mathrm{p}<0.001)$ to households with 1-5 members (12.3\%). More households $(63.2 \% ; p<0.001)$ owned $\leq 5$ acres of land than those who owned 6-10 acres (25.4\%), and $>10$ acres (11.4\%). There was no significant association in the proportions of age categories, household and land size among the districts ( $p>$ $0.05)$.

\subsection{Acquisition of Goats}

A part from offsprings produced, goat owners acquired indigenous goats mainly by purchase from livestock markets and from other farmers (Table 2). Other ways of acquiring goats were through barter trade with chicken and food crops, government programs and NGOs, gifts and dowry. Irrespective of district, exotic goats and their crosses were acquired mainly from government programs and non-government organisations (proportion 0.34, $\mathrm{n}=41$ ). Other farmers acquired exotic goats and crosses by buying (proportion 0.32), barter trade with chicken (0.27) and gifts (0.22), but neither by dowry nor exchange for food crops. 
Table 2. Means of acquiring indigenous goats by owners

\begin{tabular}{|c|c|c|c|c|c|c|c|}
\hline \multirow[b]{2}{*}{$\begin{array}{l}\text { Means of acquiring } \\
\text { goats }\end{array}$} & \multicolumn{5}{|c|}{ Ranking (Proportion of households) $^{1}$} & \multirow[b]{2}{*}{$\begin{array}{c}\text { Total } \\
(\mathrm{n}=107)\end{array}$} & \multirow[b]{2}{*}{ p-value } \\
\hline & $\begin{array}{c}\text { Kumi } \\
(\mathrm{n}=26)\end{array}$ & $\begin{array}{c}\text { Kaberamaido } \\
(\mathrm{n}=25)\end{array}$ & $\begin{array}{c}\text { Soroti } \\
(\mathrm{n}=17)\end{array}$ & $\begin{array}{r}\text { Katakwi } \\
(\mathrm{n}=19) \\
\end{array}$ & $\begin{array}{c}\text { Pallisa } \\
(\mathrm{n}=20)\end{array}$ & & \\
\hline Bought & $1(0.92)$ & $1(0.88)$ & $1(0.82)$ & $1(0.90)$ & $1(0.70)$ & $1(0.85)$ & $0.267^{\mathrm{ns}}$ \\
\hline $\begin{array}{l}\text { Sale/exchange of } \\
\text { chicken }\end{array}$ & $2(0.5)$ & $5(0.04)$ & $2(0.06)$ & $2(0.32)$ & $2(0.35)$ & $2(0.26)$ & $0.001 * *$ \\
\hline $\begin{array}{l}\text { Government and } \\
\text { NGOs }\end{array}$ & $6(0.08)$ & $2(0.20)$ & $5(0.06)$ & $3(0.32)$ & $4(0.10)$ & $3(0.15)$ & 0.126 \\
\hline Gifts & $3(0.35)$ & $6(0)$ & $3(0.06)$ & $4(0.05)$ & $3(0.15)$ & $4(0.13)$ & $0.003 * *$ \\
\hline Dowry & $4(0.27)$ & $3(0.12)$ & $4(0.06)$ & 0 & $5(0)$ & $5(0.1)$ & $0.013 *$ \\
\hline $\begin{array}{l}\text { Exchange for food } \\
\text { crops }\end{array}$ & $5(0.08)$ & $4(0.08)$ & $6(0)$ & $5(0.05)$ & $6(0)$ & $6(0.05)$ & $0.561^{\mathrm{ns}}$ \\
\hline
\end{tabular}

${ }^{1}$ The proportions were calculated by dividing the number of households that acquired goats by particular way by the number of households interviewed in a district. The greater the proportion, the more important is the means of acquiring goats.

${ }^{*} \mathrm{p}<0.05, * * \mathrm{p}<0.01$ : proportion of households across districts significantly different. ns, no significant difference, by Chi-squared test

\subsection{Reasons for Keeping Goats}

The important reasons for keeping goats in the five districts are reported in Table 3. A large percentage of farmers $(98.2 \%)$ indicated cash income from sale of goats as important in goat farming, followed by socio-cultural values (69.3\%), meat (59.6\%). A few farmers in Soroti (47\%) and Pallisa (25\%) considered goat meat production as important. Irrespective of the district, only a few farmers kept goats for manure (27.2\%), skins $(15.8 \%)$ and milk $(1.75 \%)$ all of which were ranked very low.

Table 3. Reasons for keeping goats as perceived by respondents in Teso region, Uganda

\begin{tabular}{cccccccc}
\hline & \multicolumn{7}{c}{ Households $^{\mathrm{a}}$} \\
\cline { 2 - 6 } Purpose & $\begin{array}{c}\text { Kumi } \\
\mathrm{n}=27)\end{array}$ & $\begin{array}{c}\text { Kaberamaido } \\
(\mathrm{n}=25)\end{array}$ & $\begin{array}{c}\text { Soroti } \\
(\mathrm{n}=23)\end{array}$ & $\begin{array}{c}\text { Katakwi } \\
(\mathrm{n}=19)\end{array}$ & $\begin{array}{c}\text { Pallisa } \\
(\mathrm{n}=20)\end{array}$ & $\begin{array}{c}\text { Total } \\
(\mathrm{n}=114)\end{array}$ & $\mathrm{p}$-value \\
\hline Cash sale & $27(10)$ & $24(96)$ & $23(100)$ & $19(100)$ & $19(95)$ & $112(98.2)$ & $0.527^{\mathrm{ns}}$ \\
Socio-cultural & $22(81.5)$ & $20(80)$ & $12(52.2)$ & $12(63.2)$ & $13(65)$ & $79(69.3)$ & $0.141^{\mathrm{ns}}$ \\
Meat for sale and home & $21(77.8)$ & $17(68)$ & $11(47.8)$ & $14(73.7)$ & $5(25)$ & $68(59.6)$ & $0.002^{* *}$ \\
Manure & $4(14.8)$ & $4(16)$ & $4(17.4)$ & $9(47.4)$ & $10(50)$ & $31(27.2)$ & $0.023^{*}$ \\
Skins & $9(33.3)$ & $2(8)$ & $2(8.7)$ & $4(21.1)$ & $1(5)$ & $18(15.8)$ & $0.034^{*}$ \\
Milk for sale and home & $1(3.7)$ & $1(4)$ & $0(0)$ & $0(0)$ & $0(0)$ & $2(1.75)$ & $0.657^{\text {ns }}$ \\
\hline
\end{tabular}

${ }^{\text {a } H o u s e h o l d s ~ r a n k i n g ~ p u r p o s e ~ a s ~ i m p o r t a n t ~(i . e ., ~ 1, ~ 2, ~} 3$ or just a tick). Percentages in parentheses.

${ }^{*} \mathrm{p}<0.05,{ }^{*} \mathrm{p}<0.001$, importance of goats is significantly different across districts, ns = no significant difference, by Chi-squared test

Table 4 shows the index ranking by farmers for the various reasons of keeping goats. The ranking was highest for cash income and ranged between 0.44 and 0.52 . Use of goats for socio-cultural values such as dowry for marriage and gifts was ranked second with index 0.21 to 0.24 except in Katakwi district, where they were ranked third (index 0.18).

Table 4. Purpose of keeping indigenous goats as ranked (index) by respondents in Teso region, Uganda

\begin{tabular}{cccccc}
\hline & \multicolumn{3}{c}{ Ranking (Index) } \\
\cline { 2 - 6 } Purpose & $\begin{array}{c}\text { Kumi } \\
(\mathrm{n}=27)\end{array}$ & $\begin{array}{c}\text { Kaberamaido } \\
(\mathrm{n}=25)\end{array}$ & $\begin{array}{c}\text { Soroti } \\
(\mathrm{n}=23)\end{array}$ & $\begin{array}{c}\text { Katakwi } \\
(\mathrm{n}=19)\end{array}$ & $\begin{array}{c}\text { Pallisa } \\
(\mathrm{n}=20)\end{array}$ \\
\hline Cash sale & $1(0.44)$ & $1(0.47)$ & $1(0.47)$ & $1(0.45)$ & $1(0.52)$ \\
Socio-cultural & $2(0.24)$ & $2(0.24)$ & $2(0.23)$ & $3(0.18)$ & $2(0.21)$ \\
Meat for sale and home & $3(0.22)$ & $3(0.22)$ & $3(0.21)$ & $2(0.22)$ & $4(0.1)$ \\
Manure & $4(0.05)$ & $4(0.045)$ & $4(0.061)$ & $4(0.11)$ & $3(0.15)$ \\
Skins & $4(0.05)$ & $5(0.015)$ & $5(0.023)$ & $5(0.036)$ & $5(0.015)$ \\
Milk for sale and home & $6(0.008)$ & $5(0.015)$ & $6(0.00)$ & $6(0.00)$ & $6(0.00)$ \\
\hline
\end{tabular}

Index $=\operatorname{sum}$ of $[4$ for rank $1+3$ for rank $2+2$ for rank $3+1$ for tick] divided by the sum [ 4 for rank $1+3$ for rank $2+2$ for rank $3+1$ for tick] for all purposes of keeping goats. The greater the index, the greater the importance.

\subsection{Sales of Goats and Products}

In all districts, a high proportion of farmers (77\%) sold indigenous goats 12 months preceding the interview (Table 5). The proportion of households selling indigenous goats was highest $(\mathrm{p}<0.01)$ in Kumi and Kaberamaido, where indigenous goats were most predominant, than the rest of the districts. Similarly, the average number of indigenous goats sold was highest in 
Kumi $(4.5 \pm 3.3)$ and lowest in Katakwi $(2.4 \pm 3.8)$. Few exotic goats and/or crosses were sold and this was only reported in Soroti, Katakwi and Pallisa; where relatively high proportions of households kept exotic goats and/or crosses. Sales of skins and meat was generally low, i.e. $11.5 \%$ and $2.7 \%$, respectively in all districts.

Table 5. Sales of goats by district in 12 months preceding a study conducted in Teso region, Uganda

\begin{tabular}{cccccc}
\hline & & \multicolumn{2}{c}{ Indigenous goats sold } & \multicolumn{2}{c}{ Exotic and/or crosses sold } \\
\cline { 3 - 6 } District & $\mathrm{n}$ & Households & $\begin{array}{c}\text { Number of goats (Means } \pm \\
\text { SD) }\end{array}$ & Households & $\begin{array}{c}\text { Number of goats (Means } \pm \\
\text { SD) }\end{array}$ \\
\hline Kumi & 27 & 25 & $4.5 \pm 3.3$ & 0 & 0 \\
Kaberamaido & 25 & 23 & $4.5 \pm 4.5$ & 0 & 0 \\
Soroti & 23 & 11 & $2.5 \pm 3.7$ & 5 & $0.5 \pm 0.99$ \\
Katakwi & 19 & 14 & $2.4 \pm 3.8$ & 2 & $1.3 \pm 4.82$ \\
Pallisa & 20 & 15 & $3.4 \pm 4.2$ & 2 & $0.7 \pm 2.31$ \\
& & $\mathrm{p}=0.001^{* *}$ & $\mathrm{p}=0.186^{\mathrm{ns}}$ & $\mathrm{p}=0.029^{*}$ & $\mathrm{p}=0.34^{\mathrm{ns}}$ \\
\hline
\end{tabular}

$* \mathrm{p}<0.05, * * \mathrm{p}<0.01$, number of households selling particular goat breed are significantly different across districts.

${ }^{\mathrm{ns}}$ means are not significantly different.

Table 6 compares goat sales among three categories of herd size (small, medium and large) in 12 months preceding the interview. The average number of goats sold per household was biggest $(p<0.001)$ in large size herds $(12.66 \pm 9.83)$ and smallest in small size herds $(3.00 \pm 3.35)$. Although not statistically significant $(\mathrm{p}>0.05)$, male-headed and literate households sold more goats than female-headed and illiterate households, respectively (Table 6).

Table 6. Number of goats sold by herd size, sex and education level of household head in Teso region, Uganda

\begin{tabular}{ccc}
\hline & & Number of goats sold (Mean \pm SD ) \\
\hline Herd categories & $1-8$ (Small) & $3.00 \pm 3.35$ \\
& $9-19$ (medium) & $4.43 \pm 6.50$ \\
Sex of HH & $\geq 20$ (Large) & $12.66 \pm 9.83$ \\
& Male & $\mathrm{p}<0.001$ \\
& Female & $4.20 \pm 5.92$ \\
Education of HH & & $3.19 \pm 2.90$ \\
& Literate* & $\mathrm{p}=0.503$ \\
& Illiterate & $4.31 \pm 5.92$ \\
& & $2.72 \pm 3.08$ \\
\hline
\end{tabular}

HH; household head, *House head with formal education, i.e., primary level and above

It was also observed that the number of goats sold per household increased with the households' herd size $(\mathrm{r}=0.361, \mathrm{p}<$ $0.001)$. However, considering the total number of goats sold in the households interviewed $(n=114)$, about $41 \%$ of goats sold were from small flocks, $43 \%$ from medium herds and only $16 \%$ from large herds. About $31 \%$ of farmers earned less than Uganda Shillings (UGX) 50,000/- as their annual income (average exchange rate for June 2012 to June 2013 was US $\$ 1=$ 2,500 UGX) from goat production, while only $6.1 \%$ of goat farmers had their annual income from goat production above UGX 400,000 (Table 7). Majority of farmers (69.3\%) spent less than UGX 50,000 on goat production while only $3.5 \%$ spent more than UGX 400,000. The costs were incurred in acquiring veterinary services, drugs and equipment.

Table 7. Percentage of households for various categories of total income and cost of goat production in Teso region, Uganda

\begin{tabular}{|c|c|c|c|c|}
\hline \multirow[b]{2}{*}{$\begin{array}{c}\text { Category } \\
\text { (UGX) }\end{array}$} & \multicolumn{2}{|c|}{ Production income } & \multicolumn{2}{|c|}{ Production cost } \\
\hline & Number of households & $\%$ & $\begin{array}{l}\text { Number of } \\
\text { households }\end{array}$ & $\%$ \\
\hline$<50,000$ & 36 & 31.6 & 79 & 69.3 \\
\hline $50,000-150,000$ & 41 & 36.0 & 28 & 24.6 \\
\hline $151,000-250,000$ & 21 & 18.4 & 3 & 2.6 \\
\hline $251,000-400,000$ & 9 & 7.9 & 0 & 0.0 \\
\hline$>400,000$ & 7 & 6.1 & 4 & 3.5 \\
\hline
\end{tabular}

Average exchange rate for June 2012 to June 2013 was US $\$ 1=2,500$ UGX 


\subsection{Market for Goats}

Majority of respondents $(85.1 \%)$ reported that the main option of selling goats was at weekly markets. Other options were home sales $(45.9 \%)$, shops $(2.8 \%)$ and least for daily markets $(0.9 \%)$. Goats at weekly markets were sold to traders who acted as middle men. Most goat farmers across all districts (93.5\%) cited high taxation as a problem faced in the marketing of goats and their products. Other farmers also mentioned low prices offered by traders $(79.4 \%)$ and occasional low demand for goats $(29 \%)$. The problem of long distances and/or lack of transport to the market was least cited by the farmers $(12.1 \%)$.

\subsection{Gender Aspects of Goat Production and Marketing}

Table 8 shows a summary of patterns of goat ownership and decision making in goat production by gender and district. Joint family ownership of goats and decision making to sell or give away goats was the most predominant followed by ownership by men. Fewer cases of women and children having independent ownership were reported. There was a positive correlation $(\mathrm{r}=0.818, \mathrm{p}=0.09)$ between goat ownership and decision making by men. However, the correlation for women $(\mathrm{r}$ $=0.036, \mathrm{p}=0.95)$, though positive, was less than for men. On average, male-headed and literate households owned more goats, i.e., $9.96 \pm 9.59$ and $10.11 \pm 9.58$, respectively than female-headed (7.62 \pm 3.11$)$ and illiterate $(7.11 \pm 4.10)$ households.

Table 8. Patterns of goat ownership and decision making in sale and give away of goats and goat products across districts of Teso region, Uganda

\begin{tabular}{|c|c|c|c|c|c|c|}
\hline \multirow[b]{2}{*}{ District } & \multirow[b]{2}{*}{$\mathrm{n}$} & \multirow[b]{2}{*}{ Aspect } & \multicolumn{4}{|c|}{ Households (\%) } \\
\hline & & & Men & Women & Children & Whole family \\
\hline \multirow[t]{2}{*}{ Kumi } & 27 & Ownership & 29.6 & 11.1 & 22.2 & 63.0 \\
\hline & & Decision $^{\mathrm{a}}$ & 22.2 & 18.5 & 0.0 & 59.3 \\
\hline \multirow[t]{2}{*}{ Kaberamaido } & 25 & Ownership & 40.0 & 4.0 & 8.0 & 52.0 \\
\hline & & Decision $^{\mathrm{a}}$ & 44.0 & 12.0 & 0.0 & 44.0 \\
\hline \multirow[t]{2}{*}{ Soroti } & 22 & Ownership & 36.4 & 4.5 & 0.0 & 63.6 \\
\hline & & Decision $^{\mathrm{a}}$ & 40.9 & 0.0 & 0.0 & 59.1 \\
\hline \multirow[t]{2}{*}{ Katakwi } & 19 & Ownership & 36.8 & 21.1 & 31.6 & 52.6 \\
\hline & & Decision $^{\mathrm{a}}$ & 15.8 & 21.1 & 0.0 & 63.2 \\
\hline \multirow[t]{2}{*}{ Pallisa } & 20 & Ownership & 60.0 & 35.0 & 5.0 & 20.0 \\
\hline & & Decision $^{\mathrm{a}}$ & 60 & 5.0 & 0.0 & 35.0 \\
\hline
\end{tabular}

${ }^{\mathrm{a}}$ Decision making to sell or give away goats and products.

Note: In $16 \%$ of households, goats were owned by at least two different persons.

All family members contributed to labour with regard to goat production. Overall, men were more involved (64\%) in the health care for goats than women $(32.5 \%)$ and children $(8.8 \%)$ (Table 9$)$. In some cases, more than one category of family members was indicated for provision of labour. However, in all districts women and children provided more labour for tethering/grazing and watering for goats than men.

Table 9. Provision of labour for goat production by gender among districts of Teso region

\begin{tabular}{|c|c|c|c|c|c|}
\hline \multirow[b]{2}{*}{ District } & \multirow[b]{2}{*}{$\mathrm{n}$} & \multirow[b]{2}{*}{ Role } & \multicolumn{3}{|c|}{ Percentage of households } \\
\hline & & & Men & Women & Children \\
\hline \multirow[t]{3}{*}{ Kumi } & 27 & Provision of water & 63.0 & 96.3 & 74.1 \\
\hline & & Animal health care & 59.3 & 51.9 & 11.1 \\
\hline & & Tethering/grazing & 70.4 & 96.3 & 77.8 \\
\hline \multirow[t]{3}{*}{ Kaberamaido } & 25 & Provision of water & 24.0 & 76.0 & 80.0 \\
\hline & & Animal health care & 52.0 & 20.0 & 4.0 \\
\hline & & Tethering/grazing & 56.0 & 76.0 & 76.0 \\
\hline \multirow[t]{3}{*}{ Soroti } & 23 & Provision of water & 60.9 & 100 & 73.9 \\
\hline & & Animal health care & 73.9 & 13.0 & 13.0 \\
\hline & & Tethering/grazing & 69.6 & 95.7 & 78.3 \\
\hline \multirow[t]{3}{*}{ Katakwi } & 19 & Provision of water & 52.6 & 89.5 & 78.9 \\
\hline & & Animal health care & 78.9 & 21.1 & 0.0 \\
\hline & & Tethering/grazing & 57.9 & 89.5 & 73.7 \\
\hline \multirow[t]{3}{*}{ Pallisa } & 20 & Provision of water & 45.0 & 95.0 & 55.0 \\
\hline & & Animal health care & 60.0 & 55.0 & 15.0 \\
\hline & & Tethering/grazing & 45.0 & 75.0 & 65.0 \\
\hline
\end{tabular}

Total households $=114$. In some cases, the informants indicated more than one category of people (men, women, children) that carried out the activities. 


\section{Discussion}

Results of the present study indicate that the production system in Teso region is mainly smallholder of mixed crop and livestock. The high literacy level in the study area is strength in enhancing goat production, because literate communities are more likely adopt and practice new technologies, which may enhance commercialisation of enterprises [13,15]. A considerable proportion of farmers $(41.2 \%)$ fell above 50 years of age. This could be attributed to the fact that tendering of the goats under tethering system, which was predominant in the area, requires less attention. Therefore, it was easier for older people to manage goats with this system. The fact that the youth (18-30 years) were only $11.4 \%$ of the farmers means that the enterprise is missing out on a more active group, who would enhance productivity and commercialisation. Most households $(63.2 \%)$ owned five or less acres of land. Since land is required for the grazing of animals or for production of fodder, inadequate land limits the size of goat herds that the farmers can keep. It is therefore important to introduce or improve feeding and nutrition technologies of goat farming so as to maximise output per unit area of land. Adaptive research and development based on the farmer participatory approach can lead to improved technologies including the use of fodder trees, shrubs and cactus, conservation through ensiling and the use of feed blocks [8]. Tethering is a common practice in areas where land and forage production is limiting $[11,16]$. The reduction of grazing land due to crop farming, leads to tethering of animals which in turn leads to restricted feeding. This is in turn aggravated by the poor quality feed resources in resource poor areas, which contributes to inadequate feeding and nutrition $[8,16]$. In this study, goats were fastened on one spot for most of the day, which may limit the quality and quantity of feed that they actually eat and this is likely to reduce their productivity.

Indigenous goats were mainly acquired through purchases, consistent with previous reports from other parts of Uganda [2] and in Zimbabwe [10]. Other ways were through barter trade with chicken, from government programs, gifts, dowry and exchange with food crops. Exotic goats and/or crosses were mainly acquired from government programs and buying, followed by sale/exchange of chicken and gifts. However, exotic goats and crosses were not acquired through dowry and exchange for food crops. This is because bride price is a cultural practice which involves mainly indigenous goats. Furthermore, exchange of food crops for exotic goats is difficult because such breeds cost higher than the indigenous ones. This implies that big quantities of food would be required to exchange for goats.

Information on the importance of goats to farmers is key in the success of breeding, health and feeding interventions in the tropics [4,17]. In this study, majority of the respondents ranked cash income as the most important reason for keeping goats. To a lesser extent, farmers also considered socio-cultural values and meat as important. The findings of the present study are in agreement with those of Hassen and
Tesfaye [1] in Ethiopia and Semakula et al. [2] in Uganda who reported cash income as the most important in goat farming followed by other tangible and intangible benefits. Income from goats is of utmost importance to sustain human nutrition and education for small-scale farmers [4]. Socio-cultural values were ranked second indicating the value of livestock in the cultural settings of rural communities.

A high number of farmers (77\%) marketed live goats, and very few sold meat and skins from the goats. This emphasises the finding that on-farm activities (crop and livestock) were an important source of livelihood for farmers in Teso region. This was also reported by Egeru [18] in study area. In general, few exotic goats and crosses were sold. The most likely explanation is that most farmers were in the early stages of rearing exotic goats and crosses and therefore, had very few to offer to the market. A recent study demonstrated that the genetic improvement of the production traits of the Small East African goat had a positive effect on the profitability in livestock dependent production systems in Kenya [19]. Therefore, the crossing of indigenous goats with exotic ones is likely to have a positive effect on goat productivity.

Households with large herds sold significantly more goats on average than those with medium and small herds. Such households presented a significant source of goats for the market and they could, therefore, be a target group for commercialisation. Insufficient number of goats among farmers with small herds restricts sales [15]. They, therefore, limit their sales so as to maintain the potential to expand the enterprise. However, the total number of goats sold was higher from medium and small herds. This implies that although they have limited resources, they can contribute significantly to the market. Therefore, particular attention should be paid to smallholder farmers in interventions that intend to enhance goat production, as this will increase supply of goats to the market, and thereby contributing to food security and economic growth.

Male-headed and literate households owned and sold more goats compared to female-headed and illiterate households, respectively. This may imply that the importance of goats as a source of income is more realised in male-headed and literate households than in female-headed and illiterate households. Therefore, male-headed households are in a better position to commercialise the goat enterprise. In order to have a greater impact in livestock farming, there is need to strengthen female-headed households in goat production and marketing, since they involved in ownership, decision making and provision of labour. Besides, packages that specifically target illiterate communities can be designed in the dissemination of technologies.

Most farmers (67\%) earned less than UGX 150,000 from goat production per annum (average exchange rate for June 2012 to June 2013 was US $\$ 1=2,500$ UGX), while only $6.1 \%$ had their annual income above UGX 400,000. This implies that the farmers were earning low from goats. Since most farmers owned small or medium herds (94.8\%), few 
goats and goat products were available for sell. It is therefore important to build farmers' capacity to efficiently enhance goat productivity thereby increasing income from goat production. Various studies have shown that livestock is an important source of income for a large proportion of rural households $[2,3,4]$.

In order to improve benefits from goat production, it is important to understand the opportunities and challenges faced by farmers in the marketing of goats. The main option for selling of goats was at weekly markets. To a lesser extent, sales were made at home, shops and daily markets. Goats at weekly markets were sold to traders who acted as middle men, which is in agreement with previous findings in Benin [3]. The middle men purchase animals and resale at markets and/or to butchers and caterers. In contrast, Kosgey et al. [11] reported that most goats were sold to butchers and to a lesser extent to individuals and at auctions in Kenya. The biggest problem in marketing of goats was high taxation, followed by low prices offered by traders. High taxation is explained by the fact that such rural districts generally have a low tax base, and therefore rely most on weekly livestock markets for their revenue. This is a burden to farmers, as it reduces potential benefits from goat production. It would be more beneficial if local authorities revised taxes on goat sales so as increase market flow of goats, and consequently encourage more production. The problem of low prices for goats is because livestock traders, who buy the goats, travel long distances of up to 200 kilometres. Therefore, since they bear the bulk of the transport cost, they transfer the cost to the farmers, by offering low prices. Furthermore, because of the long chain marketing which involves middlemen, the final sellers to the consumers are expected to benefit more from the goat trade at the expense of the producers [20]. The farmers were unable to make arrangements to sell their animals at periods when prices are high because most of the sales are made to solve urgent cash needs. Therefore, farmers in rural areas need to be provided with adequate and reliable market information so that they can benefit fairly from goat farming. Farmers can be advised to organise themselves into groups so that they can market their animals in better markets and in peak periods when demand is high, so that they can reap maximum benefit from sales. A group approach is necessary to overcome many of the constraints that farmers face [21]. Non-governmental organisations can be instrumental in the formation of groups, helping them to develop rules or by-laws, training leaders, developing accounting and reporting systems, and in networking them with other groups [21]. In addition, the formation of such groups creates social capital in these communities which is a valuable resource for many other activities, as demonstrated in Kenya [22]. The communities need to participate in the crucial areas of service provision, animal health delivery, marketing and quality control which strongly influence development [22]. Groups also play critical roles in obtaining breeding stock as well as in the exchange of information and providing access to veterinary services [21].
Ownership and decision to sell or give away goats was done mainly by the whole family. Fewer cases of women owning goats independently were reported, whilst ownership by children was the least reported in all districts. In contrast, other researchers have reported predominance of men in ownership and decision making with regard to goat production $[2,15]$. Although some women and youths owned goats, a few made independent decisions as regards to sales. Similar findings on the ownership and decision making in livestock production by women have been reported in South Africa [23] and West Africa [24]. Limited decision making by women may suggest that the concept of gender imbalance is common among rural communities, and is as a result of a strong cultural background biased against women. Although women play an important role in production and marketing in agro-pastoral systems, their ability to benefit from the system depends on the scale of involvement and their role in decision making and access to economic resources [24]. It is therefore important to enhance the capacity of women and strengthen their resource base so as to enable them play an active role and achieve maximum benefit from agricultural production.

All family members contributed to labour with regard to goat production. Overall, men were more involved in the health care for goats than women and children. However, women and children provided more labour for tethering/grazing and watering for goats than men. Since the goats were tethered mainly in the vicinity of homesteads, this brings them closer in the cycles of women and children involvement. Furthermore, as men direct their labour towards off-farm income generating activities, they leave some of the farm work for women and children [2]. The involvement of women and children in the various aspects of goat production underlines the importance of targeting them in goat productivity improvement programs that intend to improve household nutrition and income.

\section{Conclusions}

In conclusion, goat production provides a number of socio-economic benefits which can improve on the livelihoods of communities. Regular cash income from selling of goats was the most important reason for keeping goats, followed by other tangible and intangible benefits. Women and children played an important role in rearing of goats, although they owned fewer goats than men and were less involved in decisions regarding sales. It is important to target women and children in goat productivity improvement programs that intend to improve household nutrition and income. Given the inadequacy of grazing land for goat production, it is important that farmers adopt more efficient management practices that can maximise returns from a given area. Goat owners face difficulties in marketing goats due to high taxation, and low prices offered by traders. 


\section{Acknowledgements}

The authors thank the National Agricultural Research Organization (NARO) for providing financial support for the research. We are grateful for the goat farmers and extension workers in the study area for their willingness to participate in this study.

\section{REFERENCES}

[1] A.S. Hassen, Y. Tesfaye. Sheep and goat production objectives in pastoral and agro-pastoral production systems in Chifra district of Afar, Ethiopia, Tropical Animal Health and Production, Vol. 46, Issue 8, 1467-1474, 2014.

[2] J. Semakula, D. Mutetikka, R.D. Kugonza, D. Mpairwe. Smallholder goat breeding systems in humid, sub humid and semi arid agro-ecological zones in Uganda, Global Veterinaria, Vol. 4, No.3, 83-291, 2010

[3] L.H. Dossa, C. Wollny, M. Gauly. Smallholders' perceptions of goat farming in southern Benin and opportunities for improvement, Tropical Animal Health and Production, Vol. 39, Issue 1, 49-57, 2007.

[4] D. Tadesse, M. Urge, G. Animut, Y. Mekasha. Perceptions of households on purpose of keeping, trait preference, and production constraints for selected goat types in Ethiopia, Tropical Animal Health and Production, 46, Issue 2, 363-370, 2014

[5] MAAIF, 2011. Statistical Abstract, Agricultural Planning Department, Ministry of Agriculture, Animal Industry and Fisheries. www.agriculture.go.ug/userfiles/Statistical Abstract 2011.pdf (accessed June 7, 2013).

[6] UBOS, 2014. Statistical Abstract, Uganda Bureau of Statistics. Retrieved December 20, 2014, www.ubos.org/onlinefiles/uploads/ubos/statistical_abstracts/ Statistical_Abstract_2014.pdf.

[7] G.P. Juma, M. Ngigi, I. Baltenweck, A.G. Drucker. Consumer demand for sheep and goat meat in Kenya, Small Ruminant Research, Vol. 90, Issues 1-3, 135-138, 2010.

[8] H.B. Salem, T. Smith. Feeding strategies to increase small ruminant production in dry environments, Small Ruminant Research, Vol. 77, Issues 2-3, 174-194, 2008.

[9] P. Ebanyat, N. de Ridder, A. de Jager, R.J. Delve, M.A. Bekunda, K.E. Giller. Drivers of land use change and household determinants of sustainability in smallholder farming systems of Eastern Uganda, Population and Environment, Vol. 31, Issue 6, 474-506, 2010

[10] N. Assan, M. Sibanda. Goat production in the smallholder section in the Matobo district in semi arid areas of Zimbabwe, Agricultural Advances, Vol. 3, No. 8, 218-228, 2014

[11] I.S. Kosgey, G.J. Rowlands, J.A.M. van Arendonk, R.L. Baker. Small ruminant production in smallholder and pastoral/extensive farming systems in Kenya, Small Ruminant Research, Vol. 77, Issue 1, 11-24, 2008.
[12] S.T.A. Aslan, K.S. Gundogdu, E. Yaslioglu, M. Kirmikil, I. Arici. Personal, physical and socio-economic factors affecting farmers' adoption of land consolidation, Spanish Journal of Agricultural Research, Vol. 5, No. 2, 204-213, 2007.

[13] H. Cicek, Y. Cevger, M. Tandogan. Socio-economic factors affecting the level of adoption of innovations in dairy cattle enterprises, Ankara Üniversitesi Veteriner Fakültesis Dergisi, Vol. 55, 183-187, 2008.

[14] J. Rowlands, S. Nagda, E. Rege. Design, execution and analysis of livestock breed Surveys- a case study in Zimbabwe. A report to Food and Agricultural Organization International Livestock research Institute, Nairobi, pp. 1-4, 2003.

[15] S. Homann, A. van Rooyen, T. Moyo, Z. Nengomasha. Goat production and marketing: Baseline information for semi-arid Zimbabwe. Matopos Research Station, Bulawayo, Zimbabwe: International Crops Research Institute for the Semi-Arid Tropics, 84 pp., 2007.

[16] D.K. Nampanzira, J.D. Kabasa, S.A. Nalule, I. Nakalembe, J.R.S. Tabuti. Characterization of the goat feeding system among rural small holder farmers in the semi-arid regions of Uganda, SpringerPlus, Vol. 4, 188, 2015.

[17] I.S. Kosgey, R.L. Baker, H.M.J. Udo, J.A.M. van Arendonk. Successes and failures of small ruminant breeding programmes in the tropics: a review, Small Ruminant Research, Vol. 61, Issue 1, 13-28, 2006.

[18] A. Egeru. Role of indigenous knowledge in climate change adaptation: A case study of the Teso sub-region, Eastern Uganda, Indian Journal of Traditional Knowledge, Volume 11 No. 2, 217-224, 2012.

[19] S. Mbuku, I. Kosgey, M. Okeyo, A. Kahi. Economic values for production and functional traits of Small East African goat using profit functions, Tropical Animal Health and Production, Vol. 46, Issue 5, 789-795, 2014.

[20] I.G.S. Budisatria. Dynamics of small ruminant development in Central Java, Indonesia. PhD Thesis, Animal Production Systems Group, Wageningen University, pp. 66-110, 2006.

[21] J. De Vries. Goats for the poor: Some keys to successful promotion of goat production among the poor, Small Ruminant Research, Vol. 77, Issues 2-3, 221-224, 2008.

[22] C.O. Ahuya, A.M. Okeyo, Mwangi-Njuru, C. Peacock. Developmental challenges and opportunities in the goat industry. The Kenyan experience, Small Ruminant Research, Vol. 60, Issues 1-2, 197-206, 2005.

[23] E.C. Webb, M.J. Mamabolo. Production and reproduction characteristics of South African indigenous goats in communal farming systems, South African Journal of Animal Science, Vol. 34, supplement 1, 236-239, 2004.

[24] J. Osei-Adu, S.A. Ennin, B.O. Asante, A. Adegbidi, M. Mendy, A. Kergna. Gender issues in crop-small ruminant integration in West Africa, International Journal of Agricultural Extension, Vol. 3, Issue 2, 137-147, 2015. 